\title{
Development and Experimental Research of TBM Integrated Cutter System Based on Topological Structure Theory of Planar Mechanism
}

\section{Zhichao Meng}

School of Mechanical Engineering, Dalian University of Technology

Dongjian Yang ( $\nabla$ yangdongjian@mail.dlut.edu.cn )

College of mechanical engineering, Dalian University of Technology https://orcid.org/0000-0003-26109007

\section{Junzhou Huo}

School of Mechanical Engineering, Dalian University of Technology

\section{Puzhou Zhuo}

China Railway Engineering Equipment Group Co., Ltd.

\section{Youneng Bao}

School of Mechanical Engineering, Dalian University of Technology

\section{Original Article}

Keywords: TBM, Automatic cutters change, Integrated cutter system, Topological structure theory, AHP

Posted Date: April 20th, 2020

DOl: https://doi.org/10.21203/rs.3.rs-22824/v1

License: (c) (i) This work is licensed under a Creative Commons Attribution 4.0 International License. Read Full License 


\section{Title page}

\section{Multi-objective Optimization Design of a Heavy Duty Folding Mechanism and Self-discharging Equipment Development}

Lai-Rong Yin, born in 1984, is presently a associate professor at Changsha University of Science and Technology, China. He is engaged in the development of mechanical theory and equipment.

Tel:+86-13875980811; E-mail: yinlairong@ @otmail.com

Chong-Xiang Li, born in 1995, is a master degree candidate at University of Science and Technology Beijing, China.His research interests are mechanical design and manufacturing.

E-mail: family10264@163.com

Juan Huang, born in 1983, is presently a lecturer at Hunan Agriculture University, China. She is engaged in the development of mechanical theory and equipment.

Tel:86-18229746005; E-mail: 35488869@qq.com

Bo Wen, born in 1998, is a master degree candidate at Changsha University of Science and Technology, China.His research interests are mechanical design and manufacturing.

E-mail: 2297193353@qq.com

Jin-Hang Wang, born in 1997, is a master degree candidate at Changsha University of Science and Technology, China. His research interests are mechanical design and manufacturing.

E-mail: 2847409906@qq.com

Corresponding author: Lai-Rong Yin E-mail: yinlairong@hotmail.com

Juan Huang E-mail: 35488869@qq.com 


\title{
Multi-objective Optimization Design of a Heavy Duty Folding Mechanism and Self-discharging Equipment Development
}

\author{
Lai-Rong Yin1,4 $\bullet$ Chong-Xiang Li2 •Juan Huang $•$ Bo Wen 1 Jin-Hang Wang1,4
}

\begin{abstract}
In this paper, we investigated the technical problem of the recovery of overlength and heavy load conveying booms of self-unloading ships. A method of folding the conveying boom with a hydraulic-four-bar mechanism is presented, and by using a mathematical model for the optimization of folding speed stationary with ADAMS software, the optimization data and results were obtained. The multi-objective optimization index is introduced, and the multi-objective optimization problem is discussed. The results of the multi-objective optimization showed that parameters such as angular velocity and the change of angular acceleration of the conveyor boom were optimized. The paper has manufactured the connecting rod mechanism, and developed the self-discharging folding conveyance equipment. Through practical application, we determined that the developed folding conveying equipment had the advantages of smooth movement and high folding efficiency.
\end{abstract}

Keywords: Four-bar linkage - Optimization design $•$ Kinematic analysis $\bullet$ Equipment development

\section{Introduction}

The traditional self-unloading sand-ship often uses a fixed overhanging boom to unload sand. The key technical problems with this, such as the large size, unreturnable belt frame and poor safety, need to be solved urgently. In order to solve these problems, researchers have obtained a series of results, which have been summed into four solutions: telescopic, rotary, folding and flip. Among them, the folding boom recovery scheme was first proposed in [1],

Lai-Rong Yin, yinlairong@hotmail.com

Juan Huang, 35488869@qq.com

1 School of Automotive and Mechanical Engineering, Changsha University of Science and Technology, Changsha 410114,China

2 School of Mechanical Engineering, University of Science and Technology Beijing,Beijing 100083, China

3 Orient Science and Technology College, Hunan Agriculture University, Changsha 410128, China

4 Hunan Provincial Key Laboratory of Intelligent Manufacturing Technology for High-performance Mechanical Equipment, Changsha University of Science and Technology, Changsha 410114, China which uses the hydraulic-four-bar folding mechanism to realize the folding recovery of a 43.8 meter two-section boom (also the object of this paper). The comprehensive theory of linkage mechanisms and multi-objective optimization design have been classical research focuses in the field of mechanical design. Optimization design has been widely studied in optimization theory, mechanical properties, and material manufacturing [2-7]. Alaa Hassan et al. [8] used the non-dominated sorting genetic algorithm version II (NSGA-II) to optimize the robot gripper design. Qiu et al. [9] provided a simple design program to optimize the design of truss beams. Yalcin et al. [10] introduced an improved optimization algorithm, which can quickly obtain the scheme of Mechanically Stabilized Earth Walls (MSEW). Rao et al. [11] proposed Rao algorithms and discussed the performance of Rao algorithms in the optimization of mechanical system parts design. Bai et al. [12] proposed a design optimization method for satellite antenna that takes into account the gap node of a biaxial drive mechanism, and used the generalized reduced gradient (GRG) algorithm to significantly reduce the peak acceleration of satellite antenna and the contact force of the gap node. Cicero et al. [13] adopted the method of topology optimization to optimize the design of the compliant mechanism, and solved the problem of hinges (single-node connections) in the design of the flexible mechanism.Li-Quan Wang et.al.[14] presented an optimal design method to optimize a novel subsea pipeline mechanical connector.Ya-Li MA et al.[15]optimized the bed structure of gantry-type machining center presented by using a light-weight design method. The solution-region method can be used to optimize the linkage mechanism [16-17], and there are still many cases where kinematics requirements need to be considered [18-20]. Gabardi et al. [21] conducted kinematics analysis of the 4-UPU fully parallel manipulator to maximize the performance parameters in the design workspace. Sajid Nisar et al. [22] proposed a new remote center of motion (RCM) mechanism design for minimally invasive surgery (MIS) robotic manipulators, and optimized and reduced the size of 
the mechanism. Matteo Russo et al. [23] optimized the parallel mechanism with 3-UPR architecture for a robotic leg application by using four different objective functions. Robert et al.[24] proposed an optimization method that enables kinematic and dynamic optimization, combined with velocity profiling of the motor/drive system. Zhang et al.[25] used genetic algorithm(GA) to optimize the kinematics property of the double blades. Liu et al.[26] used a novel optimization method to optimize the locomotion and manipulation of an 18 DOFs tetrahedron-based mechanism.

To solve the problem of self-unloading sand-ship super-long overloading transportation boom recovery, this paper proposes a hydraulic, folding transportation boom of four bar linkage. The mathematical model for folding speed stability, the hydraulic oil cylinder force optimization problem, and the multi-objective optimization problem are discussed, and made the linkage, developed a self-unloading sand-ship conveying equipment.

\section{Mathematical modeling of the optimization of the four-bar mechanism}

\subsection{Design variables and constraints}

Fig. 1 shows the schematic diagram of a four-bar folding mechanism and the related dimensions of the research object. The state shown in the figure is the initial state of complete folding,V56 is the relative velocity of the original moving part 5 relative to component 6 (that is the propulsion velocity of the hydraulic cylinder). Design variables are defined as:

$$
\begin{aligned}
X & =\left\{x_{1}, x_{2}, x_{3}, x_{4}, x_{5}, x_{6}, x_{7}, x_{8}, x_{9}\right\}^{T} \\
& =\left\{a, b, l_{1}, l_{3}, l_{5}, \theta_{1}, \theta_{2}, \theta_{3}, \theta_{4}\right\}^{T}
\end{aligned}
$$

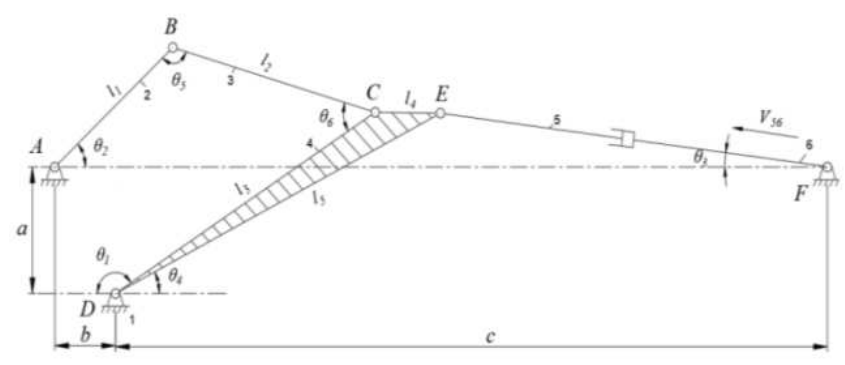

Fig. 1. Schematic diagram of four-bar mechanism motion.

Consider that the folding arm can flip $180^{\circ}$; the four-bar mechanism satisfies the bar length condition, and rotating pair $\mathrm{B}$ is the rotating pair. Set $\overline{\mathrm{AD}}$ as the shortest bar. According to the shortest bar condition and the bar length condition, the constraint conditions are as follows:

$$
\begin{gathered}
\overline{\mathrm{AD}} \leq l_{1}, \overline{\mathrm{AD}} \leq l_{2}, \overline{\mathrm{AD}} \leq l_{3} \\
\overline{\mathrm{AD}}+l_{1} \leq l_{2}+l_{3} \\
\overline{\mathrm{AD}}+l_{2} \leq l_{1}+l_{3} \\
\overline{\mathrm{AD}}+l_{3} \leq l_{1}+l_{2}
\end{gathered}
$$

\subsection{The objective function}

Kinematic analysis is the basis of studying the dynamic characteristics of the mechanism. Figs. 2 and 3 show the motion analysis diagram of the four-bar mechanism.

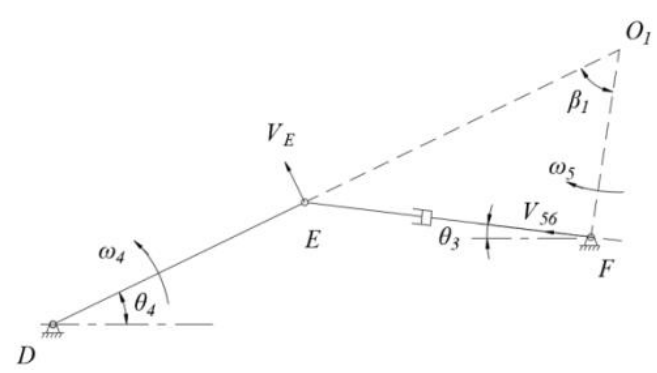

(a)Speed analysis diagram of hydraulic rod.
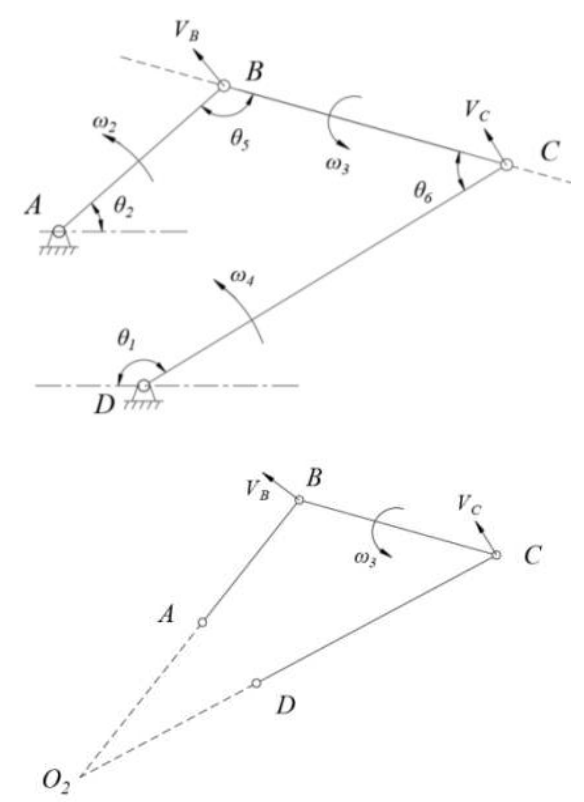

(b) Speed analysis diagram of four-bar mechanism.

Fig. 2. Speed analysis diagram of four-bar mechanism. 


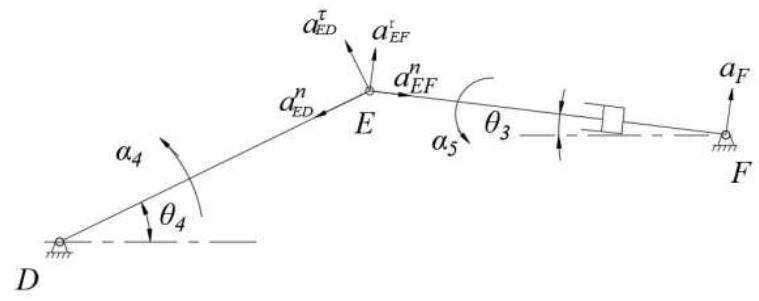

(a) Acceleration analysis diagram of hydraulic rod

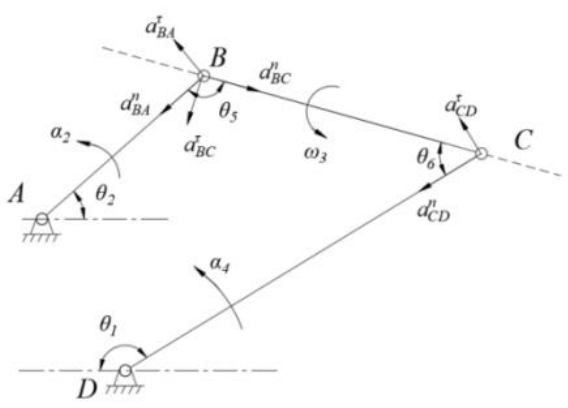

(b) Acceleration analysis diagram of four-bar mechanism

Fig. 3. Acceleration analysis diagram of four-bar mechanism

Through kinematic analysis and calculation, we deduced that the reversal angular velocity and angular acceleration of the folding arm were as follows:

$$
\begin{gathered}
\omega_{2}(X)=\frac{l_{3} V_{56} \sin \theta_{6}}{l_{1} l_{5} \sin \left(\theta_{3}+\theta_{4}\right) \sin \theta_{5}} \\
\alpha_{2}=\frac{\alpha_{4} l_{3} \sin \theta_{6}+\omega_{4}^{2} l_{3} \cos \theta_{6}-\omega_{3}^{2} l_{2}+\omega_{2}^{2} l_{1} \cos \theta_{5}}{l_{1} \sin \theta_{5}}
\end{gathered}
$$

Among them:

$$
\begin{gathered}
\theta_{5}=\arccos \frac{l_{1}+l_{3} \cos \left(\theta_{1}+\theta_{2}\right)-b \cos \theta_{2}+a \sin \theta_{2}}{l_{2}} \\
\theta_{6}=\arccos \frac{l_{3}+l_{1} \cos \left(\theta_{1}+\theta_{2}\right)-b \cos \theta_{1}-a \sin \theta_{1}}{l_{2}} \\
l_{2}=\sqrt{\left(-l_{3} \cos \theta_{1}-l_{1} \cos \theta_{2}+b\right)^{2}+\left(l_{3} \sin \theta_{1}-a-l_{1} \sin \theta_{2}\right)^{2}} \\
\omega_{3}=\frac{l_{3} V_{56} \sin \left(\theta_{5}+\theta_{6}\right)}{l_{2} l_{5} \sin \left(\theta_{3}+\theta_{4}\right) \sin \theta_{5}} \\
\omega_{4}=\frac{V_{56}}{l_{5} \sin \left(\theta_{3}+\theta_{4}\right)} \\
\omega_{5}=\frac{V_{56} \sin \theta_{3}}{\tan \left(\theta_{3}+\theta_{4}\right) \cdot\left(l_{5} \sin \theta_{4}-a\right)}
\end{gathered}
$$

$$
\begin{gathered}
V_{E}=\omega_{5} \cdot \overline{E O_{1}}=\frac{V_{56}}{\sin \left(\theta_{3}+\theta_{4}\right)} \\
\overline{\mathrm{EF}}=\frac{l_{5} \sin \theta_{4}-a}{\sin \theta_{3}} \\
\alpha_{4}=-\frac{\omega_{5}^{2} l_{5} l_{\overline{E F}}+V_{E}^{2} \cos \left(\theta_{3}+\theta_{4}\right)}{l_{5}^{2} \sin \left(\theta_{3}+\theta_{4}\right)}
\end{gathered}
$$

When working, the turning speed of the folding arm was stable. By optimizing the maximum value of angular acceleration, the stability of the velocity was optimized indirectly. The objective function of the angular velocity stability of the folding arm was as follows:

$$
F_{1}(X)=\min \left[\max \alpha_{2}(X)\right]
$$

In addition to the stability of the turning angular velocity, the force condition of the hydraulic cylinder was considered. The maximum thrust force of the hydraulic cylinder determined the diameter, which therefore affected the manufacture of the mechanism. Currently, when the complete folding state was about to be expanded, the hydraulic cylinder received a maximum thrust.

The force analysis diagram of the connecting rod mechanism is shown in Fig. 4. The thrust of the hydraulic cylinder is FE, the folding arm weight is $\mathrm{G}$, and the total length of the folding arm is L1. Through force analysis and calculation, the thrust (or tension) of the hydraulic cylinder could be obtained as follows:

$$
F_{E}(X)=\frac{G L_{1} l_{3} \sin \theta_{6}}{2 l_{1} l_{5} \sin \theta_{5} \sin \left(\theta_{3}+\theta_{4}\right)}
$$

In the process of flipping, the gravity direction was unchanged, so Eq. (18) needed to be multiplied by the coefficients of $\cos \left(\theta_{2}+\theta_{2}{ }^{\prime}\right)$ and $\theta_{2}$ ' to make the value of $\theta_{2}+\theta_{2}$ ' equal to 0 . Then Eq. (19) could be used to represent the force formula of the hydraulic cylinder in the whole folding process. When its value was regular, it was thrust, and when it was negative, it was tension.

$$
F_{E}(X)=\frac{G L_{1} l_{3} \sin \theta_{6} \cos \left(\theta_{2}+\theta_{2}^{\prime}\right)}{2 l_{1} l_{5} \sin \theta_{5} \sin \left(\theta_{3}+\theta_{4}\right)}
$$

In practical engineering, the smaller the maximum pressure required for the thrust and tension of the hydraulic cylinder, the more economical the hydraulic cylinder. Suppose the pressure required for the thrust was P1, the 
pressure required for tension was $\mathrm{P} 2$, and the maximum pressure required for hydraulic cylinder expansion and folding was Pmax. The difference between the pressure required for the maximum thrust and the pressure required for the maximum tension was $\mathrm{P}$, the diameter of the hydraulic cylinder was $\mathrm{D}$, and the diameter of the rod was $\mathrm{d}$. According to Eq. 19, the following could be obtained:

$$
\begin{gathered}
P_{1}=\frac{4 F_{E 1}}{\pi D^{2}} \\
P_{2}=\frac{4 F_{E 2}}{\pi\left(D^{2}-d^{2}\right)} \\
P=\left|P_{1 \text { max }}-P_{2 \max }\right| \\
P_{\text {max }}=\max \left\{p_{1 \text { max }}, p_{2 \text { max }}\right\}
\end{gathered}
$$

Thus, the objective function for the force optimization of the hydraulic cylinder in the four-bar linkage was as follows:

$$
F_{2}(X)=\min P_{\max }
$$

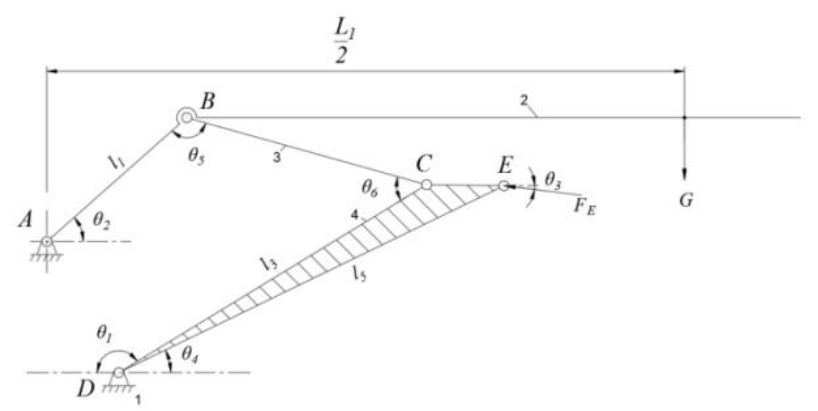

(a) Diagram of force analysis in the state of just pushing.

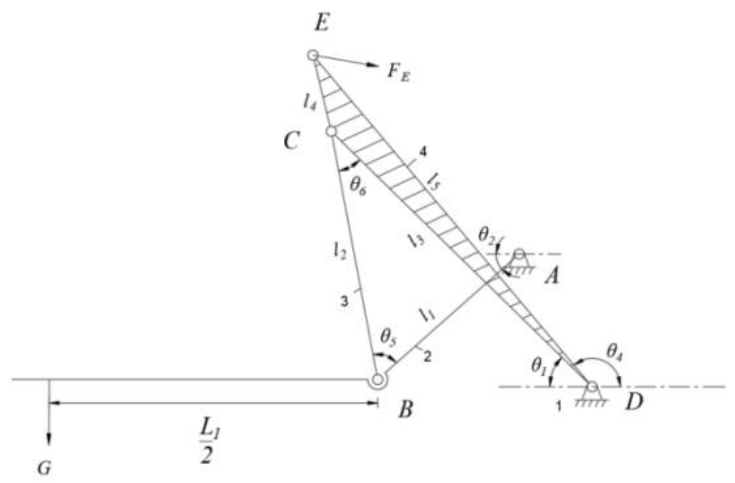

(b) Diagram of force analysis in the just-pulled state

1-Frame; 2-Folding arm; 3-The two connecting rod; 4-The three articulated connecting rod

Fig. 4. Force analysis diagram of four-bar linkage.

\section{Optimal design for speeds stationarity}

According to the optimization model for the angular velocity stability of a four-bar mechanism, we could get the optimization result of the velocity stability. However, in the actual optimization design process, too many design variables and objective functions made it difficult to express the optimization, and to achieve the optimization result. Therefore, we used ADAMS simulation software to optimize the speed stationarity of four-bar linkage. The initial calculation size of the four-link mechanism is shown in Table 1, and its parametric model is shown in Fig. 5.

Table 1 Initial dimensions of four-bar linkage

\begin{tabular}{ccccccccc}
\hline $\begin{array}{c}\text { Structure } \\
\text { size }\end{array}$ & $a$ & $b$ & $c$ & $l_{1}$ & $l_{2}$ & $l_{3}$ & $l_{4}$ & $l_{5}$ \\
\hline $\begin{array}{c}\text { The initial } \\
\text { value/mm }\end{array}$ & 400 & 220 & 3885 & 570 & 760 & 1100 & 236 & 1300 \\
\hline
\end{tabular}

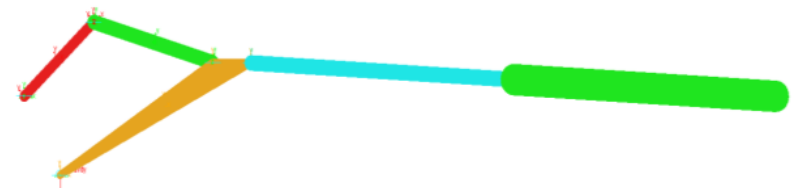

Fig. 5. ADAMS model of four-bar linkage

Nine design variable transformations for points A, B, C, $\mathrm{D}, \mathrm{E}, \mathrm{F}$ with 10 initial coordinate variables (folding arm folded state) were used with maximum angular acceleration as the optimization target. Reducing the maximum angular acceleration made four bar-linkage flip angular velocity stability optimized, and the sensitivity analysis of the 10 coordinate variables on the angular acceleration is carried out. The results are shown in Table 2.

Table 2 Design variables and sensitivity analysis results of four-bar linkage.

\begin{tabular}{ccccc}
\hline $\begin{array}{c}\text { Design } \\
\text { variables }\end{array}$ & $\begin{array}{c}\text { Design } \\
\text { point }\end{array}$ & $\begin{array}{c}\text { Coordinate } \\
\text { direction }\end{array}$ & $\begin{array}{c}\text { Initial } \\
\text { value }\end{array}$ & $\begin{array}{c}\text { Sensitivity to } \\
\text { initial } \\
\text { values/deg·s-2·m-1 }\end{array}$ \\
\hline$x_{A}$ & POINT_A & $\mathrm{X}$ & -220 & 14.72 \\
$y_{A}$ & POINT_A & $\mathrm{Y}$ & 400 & 374.58 \\
$x_{B}$ & POINT_B & $\mathrm{X}$ & 207.2 & -5.63 \\
$y_{B}$ & POINT_B & $\mathrm{Y}$ & 777.3 & 376.65 \\
$x_{C}$ & POINT_C & $\mathrm{X}$ & 939.2 & 25.87 \\
$y_{B}$ & POINT_C & $\mathrm{Y}$ & 572.7 & 170.89 \\
$x_{E}$ & POINT_E & $\mathrm{X}$ & 1175.1 & 65.46 \\
$y_{E}$ & POINT_E & $\mathrm{Y}$ & 569.8 & 880.28 \\
$x_{F}$ & POINT_F & $\mathrm{X}$ & 4405 & 2.54 \\
$y_{F}$ & POINT_F & $\mathrm{Y}$ & 400 & 168.65 \\
\hline
\end{tabular}


In Table 2 we see the impact of each design variable on the folding speed when the initial value was obtained, and we see that the sensitivity of $\mathrm{yA}, \mathrm{yB}, \mathrm{yE}$ to the folding speed was highest. Therefore, $\mathrm{yA}, \mathrm{yB}, \mathrm{yE}$ were selected as the key design variables, and Eq. 17 was used as the optimization objective function for optimization analysis. The optimization analysis results are shown in Table 3:

Table 3 Optimization analysis results

\begin{tabular}{cccc}
\hline & Initial value & Range & Optimal value \\
\hline$y_{A}$ & 400 & 300,500 & 300 \\
$y_{B}$ & 777.3 & 677,877 & 877 \\
$y_{E}$ & 569.8 & 470,870 & 670.1 \\
$\begin{array}{c}\text { Maximum angular } \\
\text { acceleration/deg.s-2 }\end{array}$ & 9.78 & & 3.49 \\
\hline
\end{tabular}

Table 3 shows that after optimization, the maximum angular acceleration of the folding arm was reduced by $64.4 \%$ in the folding process, and the stability of the folding speed of the folding arm was optimized. In order to see the stability optimization of the folding speed of the folding arm on the whole, the comparison diagram of folding angular velocity and angular acceleration of the folding arm before and after the optimization was introduced, as shown in Figs. 6 and 7. As can be seen from Figs. 6 and 7, both the folding angular velocity and the maximum folding angular acceleration of the folding arm decreased significantly after optimization, and the stability of the folding arm was optimized.

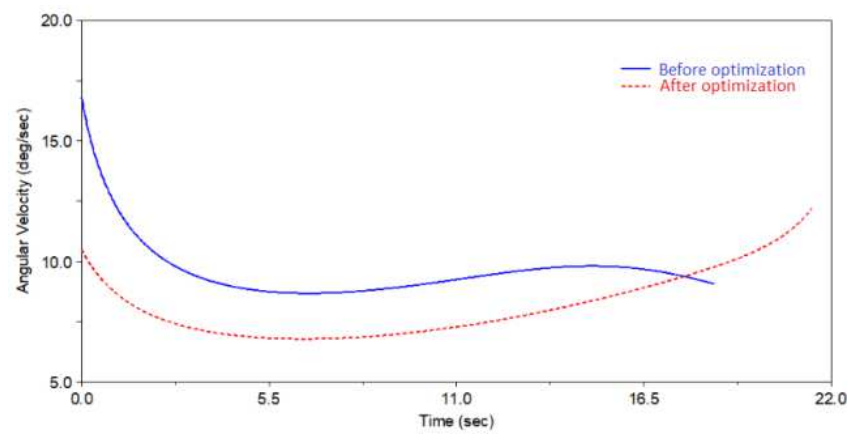

Fig. 6. The angular velocity curves of folding arms before and after optimization

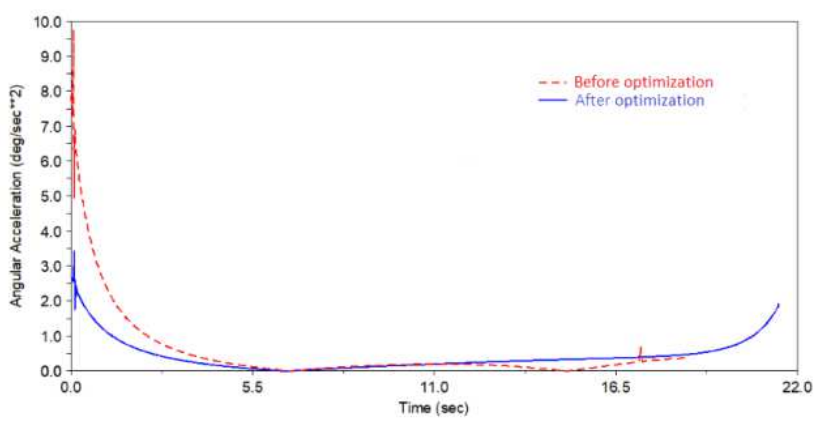

Fig. 7. The angular acceleration curves of folding arms before and after optimization

\section{Multi-objective optimization design of a four-bar mechanism}

\subsection{Multi-objective optimization design for speed Stationarity}

By referring to the unified objective function for the optimization design, an optimization index $K$ was constructed to measure the effect of the multi-objective optimization results. The expression was as follows:

$$
K=n_{1} \frac{F_{1}(X)}{F_{1}\left(X_{0}\right)}+n_{2} \frac{F_{2}(X)}{F_{2}\left(X_{0}\right)}+\ldots+n_{i} \frac{F_{i}(X)}{F_{i}\left(X_{0}\right)}
$$

$F_{i}(X)$ were the objective functions, $F_{i}\left(X_{0}\right)$ were the initial values of each objective function, $n_{i}$ was the weight factor, and $\mathrm{n}_{1}+\mathrm{n}_{2}+\ldots+\mathrm{n}_{\mathrm{i}}=1$.

Using the optimization index $K$ and simulation data, the optimization performance was calibrated more comprehensively. The expression for the speed stationarity optimization index $K$ was as follows:

$$
K_{1}=n_{1} \frac{\omega_{0 f}}{\omega_{f}}+n_{2} \frac{\omega_{0 \max }}{\omega_{\max }}+n_{3} \frac{\omega_{\min }}{\omega_{0 \text { min }}}
$$

$\omega_{f}$ was the angular velocity at the end of the folding arm expansion under different design variables, $\omega_{\max }$ was the maximum angular velocity in the expansion process, $\omega_{\min }$ was the minimum angular velocity in the expansion process, and $\omega_{0 f}, \omega 0 \max$, and $\omega 0_{\min }$ were the corresponding initial values before optimization. The initial value and the weight factor are seen in Table 4.

By looking at the study on the diagonal acceleration sensitivity of the design variables in Table 2 , it can be seen that the diagonal velocities of points $y_{E}, y_{A}, y_{B}$ had a great influence; the influence of the three variables on the 
optimization index $K_{l}$ was mainly studied. The influence of $y_{E}$ to $y_{A}$ and $y_{B}$ on the optimization index $K_{l}$ is shown in Figs. 8 and 9 .

Table 4 The value of the weight factor and the initial value of the related angular velocity

\begin{tabular}{ccccccc}
\hline & $\begin{array}{c}\omega_{0 f} \\
(\mathrm{deg} / \mathrm{s})\end{array}$ & $\begin{array}{c}\omega_{0 \max } \\
(\mathrm{deg} / \mathrm{s})\end{array}$ & $\begin{array}{c}\omega_{0 \mathrm{~min}} \\
(\mathrm{deg} / \mathrm{s})\end{array}$ & $n_{1}$ & $n_{2}$ & $n_{3}$ \\
\hline Initial value & 9.11 & 16.8 & 8.71 & 0.39 & 0.16 & 0.45 \\
\hline
\end{tabular}

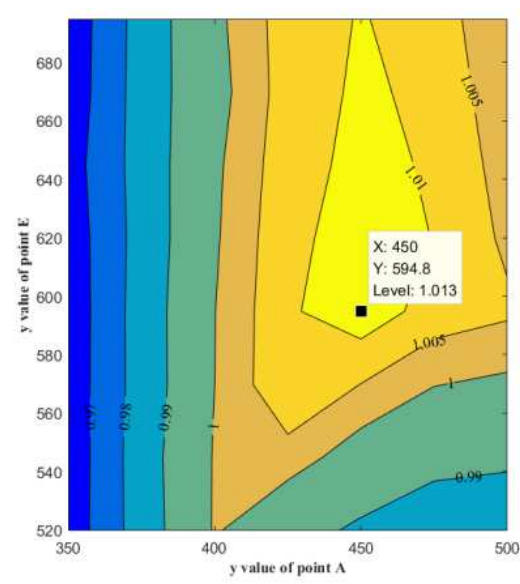

Fig. 8. Contour map of $\mathrm{K}_{1}$ (ye and yA are variables)

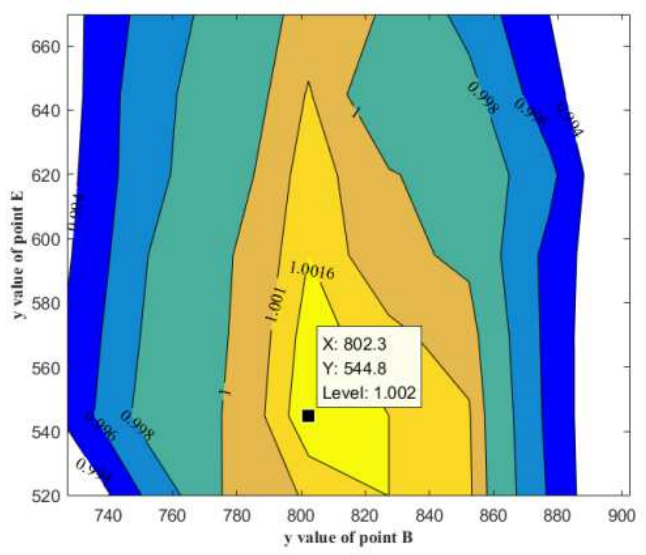

Fig. 9. Contour map of $\mathrm{K}_{1}$ (уе and ув are variables)

According to Figs. 8 and 9, we could not only obtain the optimal optimization solution under the relevant variables, but also found the relatively ideal optimization size data according to the corresponding optimization indexes. When point A was on the rack, the smaller the $y_{A}$ value was, the more compact the overall structure was. The contour map of the influence of variables $y_{E}$ and $y_{B}$ on $K_{l}$ is shown in Fig. 10. In Fig. 10, we see that when $y_{E}=544.8$ and $y_{B}=852.3, K_{1}$ reached a maximum value of
1.019 , and the optimal optimization results are shown in Table 5.

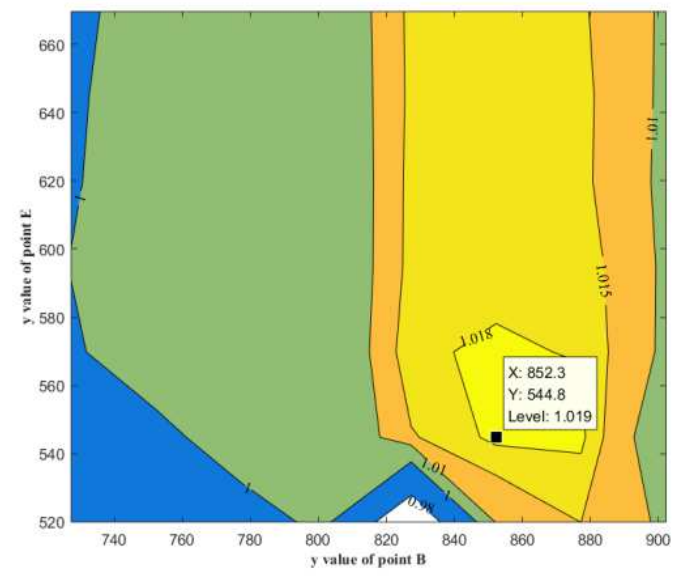

Fig. 10. Contour map of $\mathrm{K}_{1}\left(\mathrm{y}_{\mathrm{A}}=425\right.$, $\mathrm{y}_{\mathrm{E}}$ and ув are variables $)$

Table 5 Optimization results of velocity stationarity

\begin{tabular}{cccc}
\hline & $\begin{array}{c}\text { Initial } \\
\text { value }\end{array}$ & $\begin{array}{c}\text { Optimal } \\
\text { value }\end{array}$ & $\begin{array}{c}\text { Optimization } \\
\text { percentage }\end{array}$ \\
\hline$y_{A}$ & 400 & 425 & \\
$y_{\mathrm{B}}$ & 777.3 & 852.3 & \\
$y_{E}$ & 569.8 & 544.8 & \\
$l_{1} / \mathrm{mm}$ & 570 & 604.2 & $6.00 \%$ \\
$l_{2} / \mathrm{mm}$ & 760 & 783.6 & $3.10 \%$ \\
$l_{4} / \mathrm{mm}$ & 236 & 237.5 & $0.65 \%$ \\
$\omega_{\max } / \mathrm{deg} \cdot \mathrm{s}-1$ & 16.80 & 16.66 & $-0.83 \%$ \\
$\omega_{\min } / \mathrm{deg} \cdot \mathrm{s}-1$ & 8.71 & 8.80 & $+1.03 \%$ \\
$\omega_{f} / \mathrm{deg} \cdot \mathrm{s}-1$ & 9.09 & 8.82 & $-2.97 \%$ \\
\hline
\end{tabular}

\subsection{Multi-objective optimization design of a four-bar mechanism}

The force on the hydraulic cylinder and the folding speed multi-objective optimization index $\mathrm{K} 2$ were expressed as follows:

$$
K_{2}=n_{1} \frac{P_{0}}{P}+n_{2} \frac{P_{0 \max }}{P_{\max }}+n_{3} \frac{\omega_{0 \text { 终 }}}{\omega_{\text {终 }}}+n_{4} \frac{\omega_{0 \max }}{\omega_{\max }}+n_{5} \frac{\omega_{\min }}{\omega_{0 \min }}
$$

Values of the relevant data and weight factors of the hydraulic cylinder are shown in Table 6.

By Eq. (19), the maximum thrust or tension required for the hydraulic cylinder is in the starting or stopping position. Using Adams simulation data and Eq. (27), the value of optimization index $K_{2}$ can be obtained.The variables used were $y_{E}$ and $x_{F}$, and $y_{A}$ and $y_{B}$ took the optimized values in Section $4.1\left(y_{A}=425, y_{B}=852.3\right)$. When $y_{E}=519.8$ and $x_{F}=4255$, the maximum value of $K_{2}$ 
was 12.340 , and the optimization results are shown in Table 7. In practice, the folding arm was not horizontal, and the speed of the oil cylinder was low; the optimized pressure value was greater than the actual pressure value.

Table 6 Hydraulic cylinder related data and weight factor value

\begin{tabular}{cccccccc}
\hline & $D$ & $d$ & $n_{1}$ & $n_{2}$ & $n_{3}$ & $n_{4}$ & $n_{5}$ \\
\hline Initial value & 200 & 140 & 0.2 & 0.2 & 0.2 & 0.2 & 0.2 \\
\hline
\end{tabular}

Table 7 Multi-objective optimization results

\begin{tabular}{cccc}
\hline & Initial value & $\begin{array}{c}\text { Optimal } \\
\text { value }\end{array}$ & $\begin{array}{r}\text { Percentage } \\
\text { change }\end{array}$ \\
\hline$y_{A}$ & 400 & 425 & $+6.25 \%$ \\
$y_{\mathrm{B}}$ & 777.3 & 852.3 & $+9.65 \%$ \\
$y_{E}$ & 569.8 & 519.8 & $-8.78 \%$ \\
$x_{\mathrm{F}}$ & 4405 & 4255 & $-3.41 \%$ \\
$l_{1}$ & 570 & 604.2 & $+6.00 \%$ \\
$l_{2}$ & 760 & 783.6 & $+3.10 \%$ \\
$l_{4}$ & 236 & 241.8 & $+2.44 \%$ \\
$l_{5}$ & 1305 & 1284.9 & $-1.54 \%$ \\
$P / \mathrm{MPa}$ & 1.45 & 0.03 & $-97.93 \%$ \\
$P_{\max } / \mathrm{MPa}$ & 25.16 & 24.85 & $-1.23 \%$ \\
$\omega_{f} /$ deg.s-l & 9.09 & 8.95 & $-1.57 \%$ \\
$\omega_{\max } /$ deg $\cdot$ s- 1 & 16.80 & 17.59 & $+4.70 \%$ \\
$\omega_{\min } /$ deg $\cdot s-1$ & 8.71 & 8.91 & $+2.30 \%$ \\
\hline
\end{tabular}

\section{Prototype manufacturing and testing}

Prototype manufacturing is divided into the 3D printing model and physical prototype. First, SolidWorks was used to conduct 3D modelling for each part of the connecting rod mechanism, and then the 3D model file was saved in the .stl format (the 3D model was automatically layered). This was converted to the printed program file in the software Cura, and the mock-up is shown in Fig. 11.

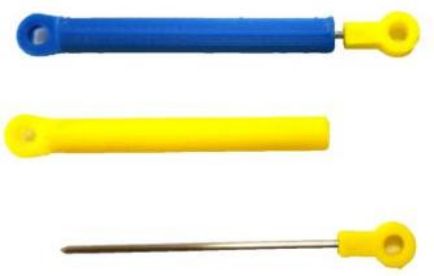

(a) Hydraulic cylinder (b) Articulated connecting rod
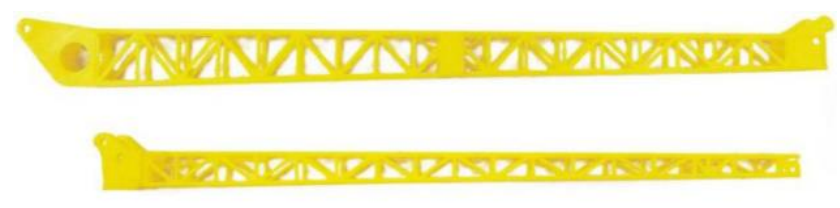

(c) Folding arm truss

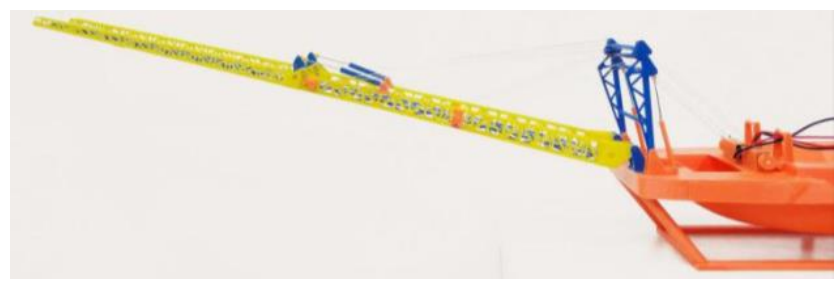

(d) Model of self-discharging transport equipment

Fig. 11. 3D printed model of each part of hydraulic connecting rod mechanism

Through actual motion analysis of the 3D printed model, the parameters meet the expectations of the optimal design. Through cooperation with Hunan Xinghuo Machinery Manufacturing Co., the self-discharging transport equipment was manufactured, as shown in Fig. 12. By using the special test platform, we see that the folding mechanism folding time was less than 12 minutes, and the maximum pressure of the hydraulic cylinder was less than $18 \mathrm{MPa}$, in line with the standards of transport equipment of self-discharging ships. The actual working test of the prototype showed that the folding time was the same as the pressure of the hydraulic cylinder, the conveying volume of the conveyor was the same as that of the traditional fixed conveyor, the conveying bandwidth was $1,400 \mathrm{~mm}$, and the conveying capacity was more than 4,000 tons/hour, thus achieving all the expected functions. 


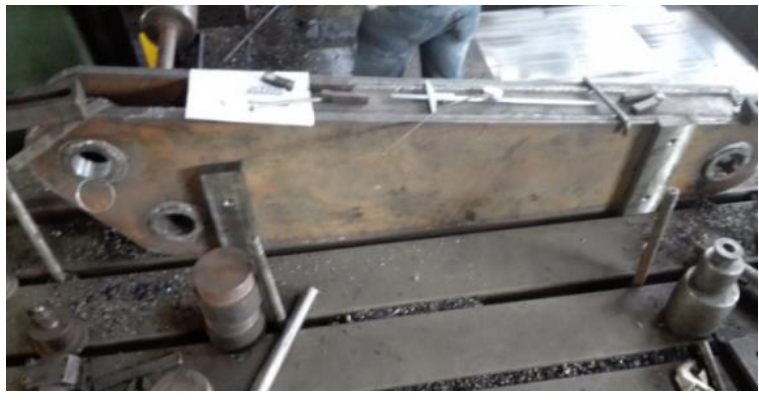

(a) The manufacturing of three pairs component

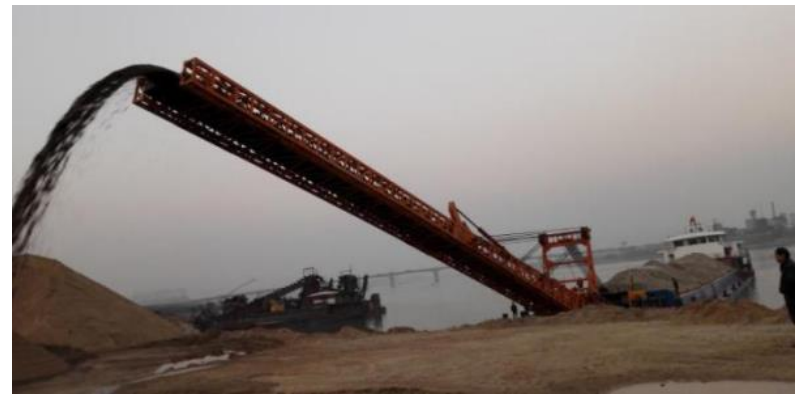

(b) Self-discharging transport ship

Fig. 12. Self-discharging equipment

\section{Conclusions}

(1) In this paper, we aimed to solve the technical problem of recovery of overlength and heavy load conveying booms of self-unloading ships. A method of a folding conveying boom with hydraulic-four-bar mechanisms was presented.

(2) The size and motion of the four-bar mechanism was optimized with multiple objectives. the results showed that parameters such as angular velocity and the change of angular acceleration of the conveyor boom were optimized.

(3) By looking at the practical applications, the developed folding conveying equipment had the advantages of smooth movement and high folding efficiency, which solved problems such as being unable to close and release the over-long and heavy-load conveying boom, a low efficiency and poor security at the source.

\section{Declaration}

\section{Acknowledgements}

The authors sincerely thanks to Zhang, general manager of Hunan Xinghuo Machinery Manufacturing Co., for providing material manufacturing and experimental space.

\section{Funding}

Supported by the National Natural Science Foundation of China (No. 51705034-51805047), the Natural Science Foundation of Hunan province (No. 2018JJ3548), the Training Program for Excellent Young Innovators of Changsha (2019-2024 Yin Lairong), and Hunan Xinghuo Machinery Manufacturing Co.

\section{Availability of data and materials}

The datasets used during the current study are available from the corresponding author on reasonable request.

\section{Authors' contributions}

Y-LR proposed the idea and methodology; L-CX derived the equations; H-J participated in the scheme design; W-B participated in the design and manufacture of folding mechanism.

\section{Competing interests}

The authors declare no competing financial interests.

\section{Consent for publication}

Not applicable

\section{Ethics approval and consent to participate}

Not applicable

\section{References}

[1] Yin L R, Huang J, Xiong G L, Hu L, Liu X, Zhang Z Y. A kind of dragon door conveyor. China, ZL201410640779.3, Invention patent, Date of authorization: 2016-9-14.

[2] Michael R.Snowdon, Mohamed Abdelwahab,et.Mechanical optimization of virgin and recycled poly(ethylene terephthalate) biocomposites with sustainable biocarbon through a factorial design.Results in Materials, 2020, 5:100060.

[3] Zhe Qu, LinYao. et. Rational design of HSNs/VO2 bilayer coatings with optimized optical performances and mechanical robustness for smart windows. Solar Energy Materials and Solar Cells, 2019, 200:109920.

[4] Matthew E.Lynch, Matthew Mordasky, Lin Cheng, Albert To. Design, testing, and mechanical behavior of additively manufactured casing with optimized lattice structure.Additive Manufacturing, 2018 , 22:462-471.

[5] Guo-Hua Song, Shi-Kai Jing, Fang-Lei Zhao, Ye-Dong Wang, Hao Xing, Jing-Tao Zhou. Design Optimization of Irregular Cellular Structure for Additive Manufacturing. Chinese Journal of Mechanical Engineering, 2017, 30(5): 1184-1192.

[6] Dong-Sheng Zhang, Yun-Dou Xu, Jian-Tao Yao and Yong-Sheng Zhao. Analysis and Optimization of a Spatial Parallel Mechanism for a New 5-DOF Hybrid Serial-Parallel Manipulator. Chinese Journal of Mechanical Engineering, 2018, 31(1): 54.

[7] Shao-Gan Ye, Jun-Hui Zhang, Bing Xu.Noise reduction of an axial piston pump by valve plate optimization. Chinese Journal of 
Mechanical Engineering, 2018, 31:57.

[8] Alaa Hassan, Mouhammad Abomoharam. Modeling and design optimization of a robot gripper mechanism. Robotics and Computer -Integrated Manufacturing, 2017, 46: $94-103$.

[9] Wenge Qiu, Feng Lu, Gang Wang .et. Evaluation of mechanical performance and optimization design for lattice girders. Tunnelling and Underground Space Technology, 2019, 87:100-111.

[10] Yagizer Yalcin, Murat Orhon, Onur Pekcan. An automated approach for the design of Mechanically Stabilized Earth Walls incorporating metaheuristic optimization algorithms. Applied Soft Computing, 2019, 74:547-566.

[11] R.V.Rao, R.B.Pawar. Constrained design optimization of selected mechanical system components using Rao algorithms.Applied Soft Computing, 2020, 89:106141.

[12] Zheng Feng Bai, Ji Jun Zhao, Jun Chen, Yang Zhao. Design optimization of dual-axis driving mechanism for satellite antenna with two planar revolute clearance joints. Acta Astronautica, 2018, 144: $80-89$.

[13] Cícero R. de Lima, Glaucio H. Paulino. Auxetic structure design using compliant mechanisms: A topology optimization approach with polygonal finite elements. Advances in Engineering Software, 2019, 129: $69-80$.

[14] Li-Quan Wang, Zong-Liang Wei, Shao-Ming Yao, Yu Guan, Shao-Kai Li. Sealing performance and optimization of a subsea pipeline mechanical connector. Chinese Journal of Mechanical Engineering, 2018, 31:18.

[15] Ya-Li Ma, Jian-Rong Tan, De-Lun Wang, Zi-Zhe Liu. Light-weight design method for force-performance-structure of complex structural part based co-operative optimization. Chinese Journal of Mechanical Engineering, 2018, 31:42.

[16] Yin Lairong, Tian Lei, Huang Long. A solution-region approach for synthesis linkages with coincident intantaneous center and one fixed pivot. Journal of Mechanical Science and Technology. 2020, 34(2): 829-834.

[17] Yin Lairong, Huang Long, Huang Juan. Solution-region-based synthesis approach for selecting optimal four-bar linkages with the Ball - Burmester point. Mechanical Sciences, 2019,10, 25-33 .

[18] Zhang X M, Lu J W, Shen Y W. Simultaneous optimal structure and control design of flexible linkage mechanism for noise attenuation. Journal of sound and Vibration, 2007, 299(4-5): 1124-1133.

[19] Pongsiri Kuresangsai, Matthew O.T.Colea. Kinematic modeling and design optimization of flexure-jointed planar mechanisms using polynomial bases for flexure curvature. Mechanism and Machine Theory,2019, 132:80-97.

[20] Wei Yea, Xinxue Chai, Ketao Zhang. Kinematic modeling and optimization of a new reconfigurable parallel mechanism. Mechanism and Machine Theory, 2020, 149:103850.

[21] M. Gabardi, M. Solazzi, A. Frisoli. An optimization procedure based on kinematics analysis for the design parameters of a 4-UPU parallel manipulator. Mechanism and Machine Theory, 2019, 133: 211-228.

[22] Sajid Nisar, Takahiro Endo, Fumitoshi Matsuno. Design and optimization of a 2-degree-of-freedom planar remote center of motion mechanism for surgical manipulators with smaller footprint. Mechanism and Machine Theory, 2018, 129: 148-161.

[23] Matteo Russo, Saioa Herrero, Oscar Altuzarra, MarcoCeccarelli. Kinematic analysis and multi-objective optimization of a 3-UPR parallel mechanism for a robotic leg. Mechanism and Machine Theory, 2018,120:192-202.

[24] Robert M.C. Rayner, M. Necip Sahinkaya, Ben Hicks. Improving the design of high speed mechanisms through multi-level kinematic synthesis, dynamic optimization and velocity profiling. Mechanism and Machine Theory, 2017, 118:100-114.

[25] ZHANG Shuangjie, YAO Yunfeng, LI Lingchong, WAGN Lijuan, LI Junxia and LI Qiang. Kinematics Analysis and Optimization of the Fast Shearing-extrusion Joining Mechanism for Solid-state Metal. Chinese Journal of Mechanical Engineering, 2015, 29(06).

[26] Ran Liu, Yan-An Yao, Wan Ding and Xiao-Ping Liu. Locomotion Optimization and Manipulation Planning of a Tetrahedron-Based Mobile Mechanism with Binary Control. Chinese Journal of Mechanical Engineering, 2018, 31(1): 11.

\section{Biographical notes}

Lai-Rong Yin, born in 1984, is presently a associate professor at Changsha University of Science and Technology, China. He is engaged in the development of mechanical theory and equipment. Tel:+86-13875980811;E-mail: yinlairong@hotmail.com

Chong-xiang Li, born in 1995, is a master degree candidate at University of Science and Technology Beijing, China.His research interests are mechanical design and manufacturing.

Juan Huang, born in 1983, is presently a lecturer at Hunan Agriculture University, China. She is engaged in the development of mechanical theory and equipment.

Tel:86-18229746005

Bo Wen, born in 1998, is a master degree candidate at Changsha University of Science and Technology, China.His research interests are mechanical design and manufacturing.

Jin-hang Wang, born in 1997, is a master degree candidate at Changsha University of Science and Technology, China. His research interests are mechanical design and manufacturing. 
Figures

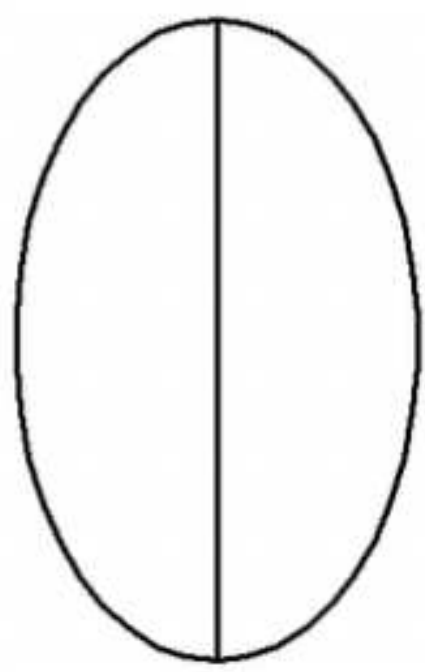

Figure 1

Topological Diagram

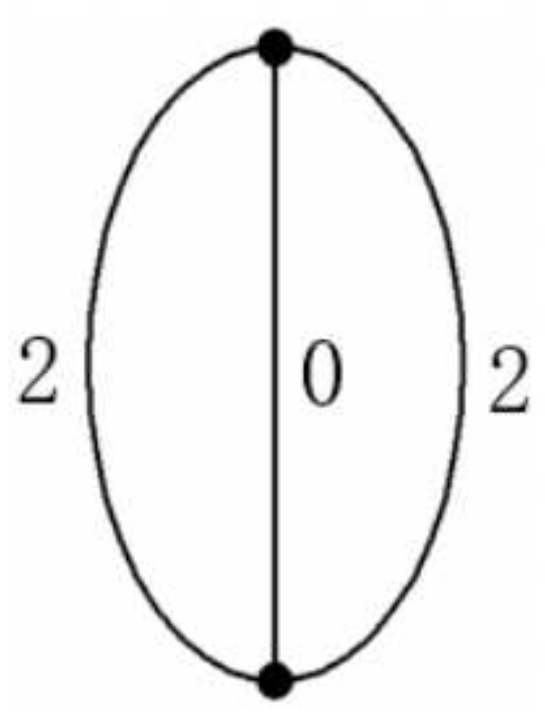

Figure 2

Weighted Topology Diagram 


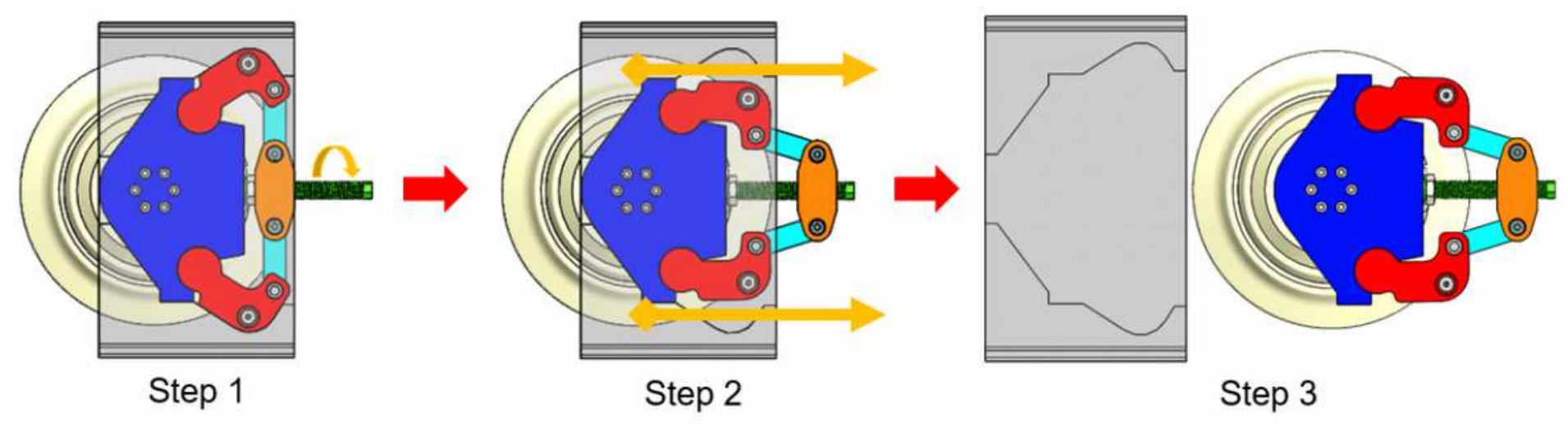

Figure 3

Schematic diagram of removing cutters

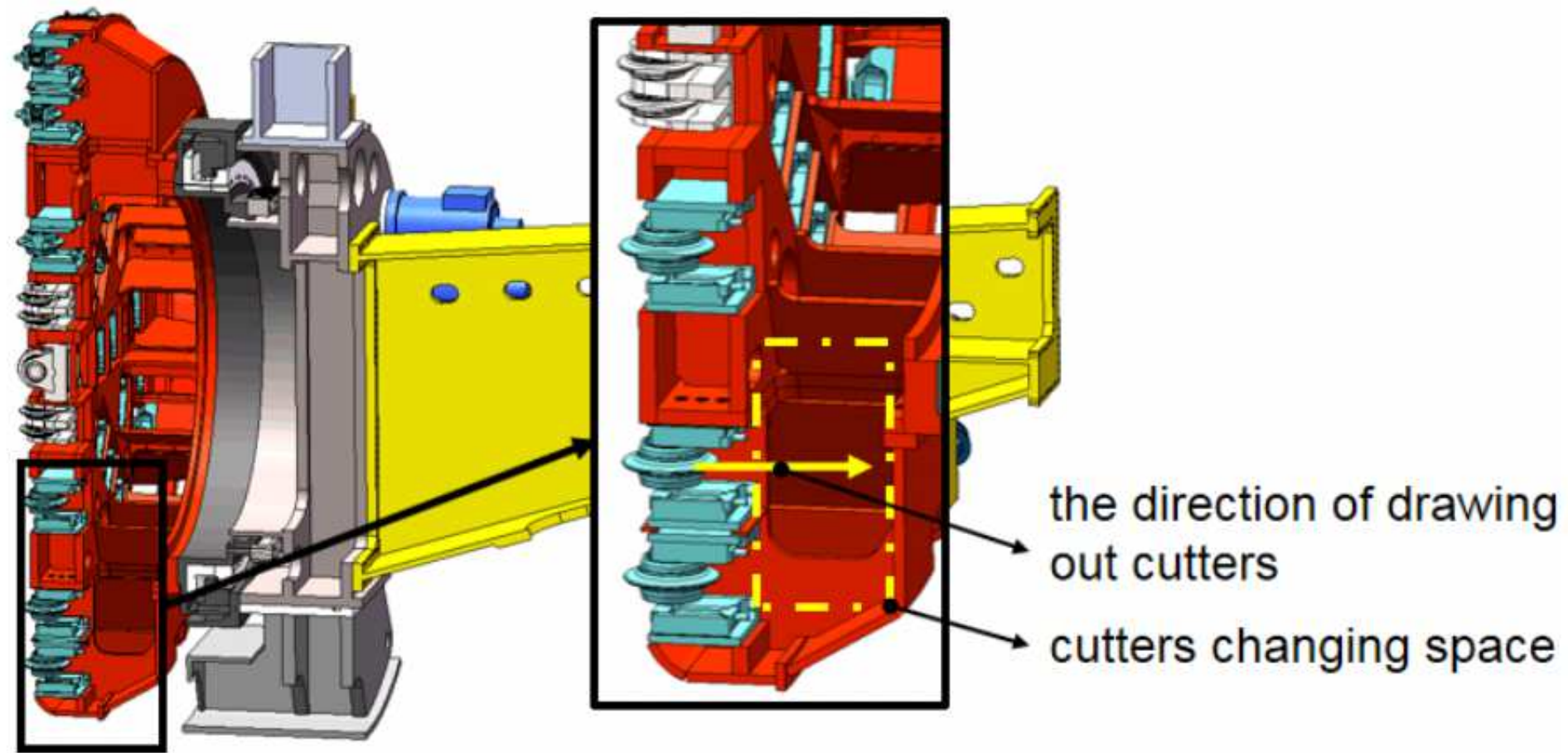

Figure 4

Schematic diagram of TBM cutters change space and drawing direction 


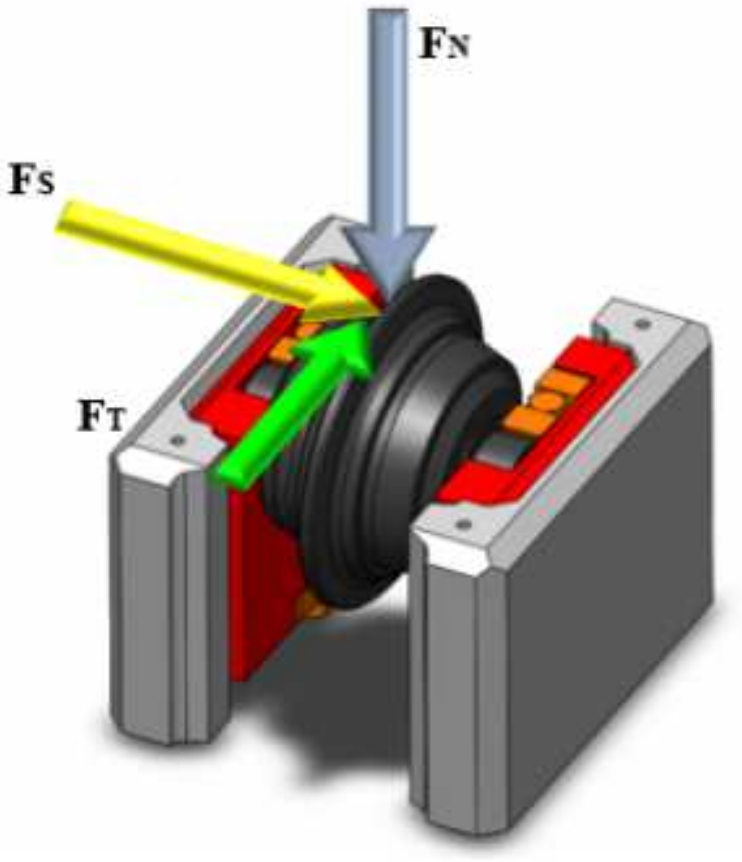

Figure 5

Schematic diagram of the force directions

A: Static Structural
Equivalent Stress
Type: Equivalent (vo
Unit: MPa
Time: 1
$2019 / 3 / 4$ 16:58

\begin{tabular}{|l}
$96.556 \mathrm{Max}$ \\
89.66 \\
82.763 \\
75.866 \\
68.969 \\
62.072 \\
55.175 \\
48.278 \\
41.381 \\
34.484 \\
27.588 \\
20.691 \\
13.794 \\
6.8969 \\
$7.9812 \mathrm{e}-9 \mathrm{Min}$
\end{tabular}
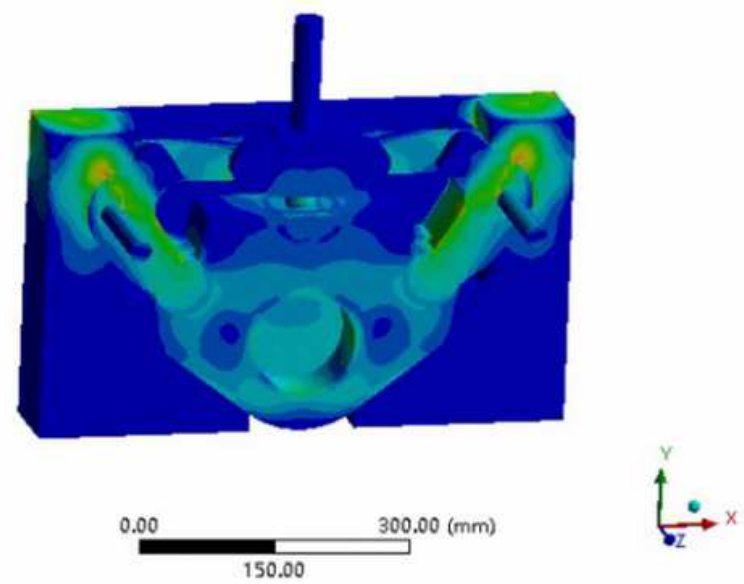

A: Static Structura

Total Deformation

Type: Total Deformation

Unit: $\mathrm{mm}$

Time: 1

2019/3/4 16:53
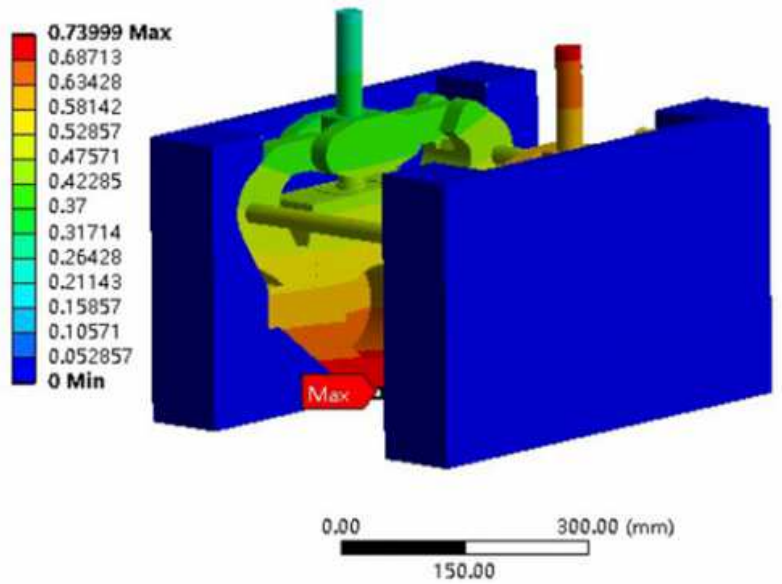

\section{Figure 6}

The results of finite element analysis of the ICS 


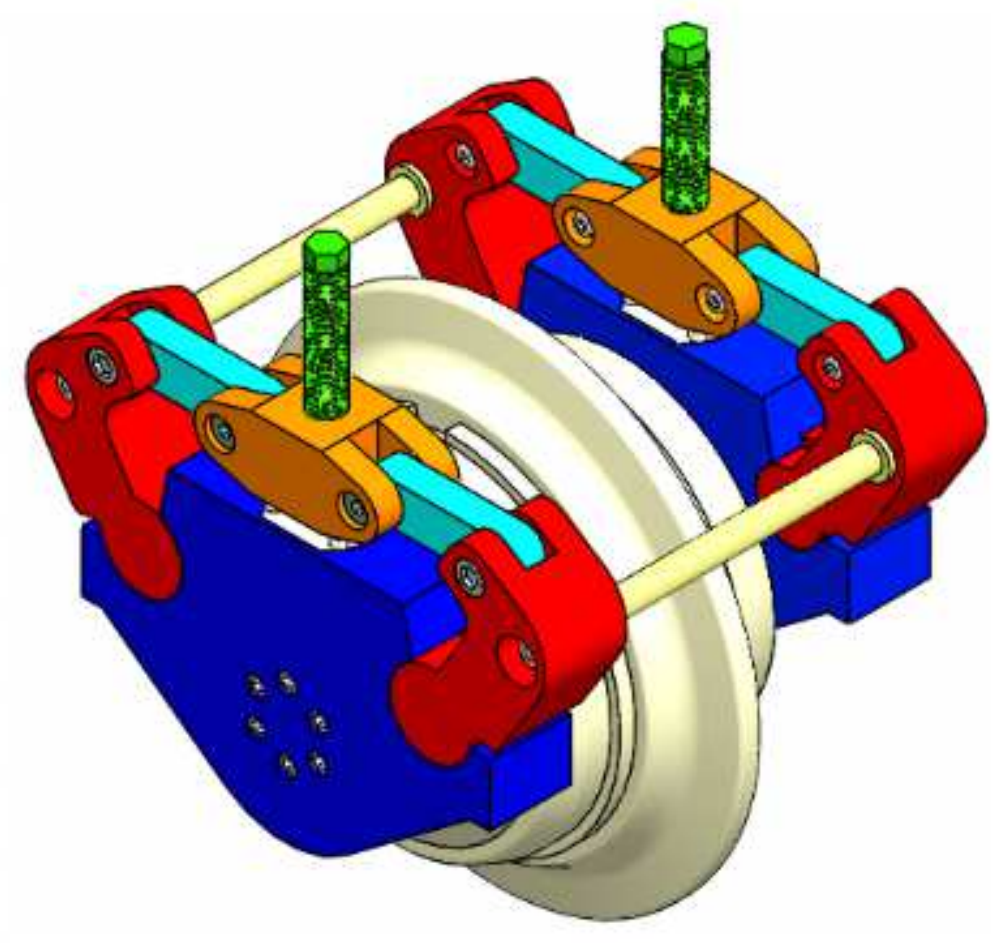

Figure 7

Schematic diagram of parts grasped by TBM cutters change robot

\section{Target layer}

\section{Criterion layer}

\section{Solution layer}

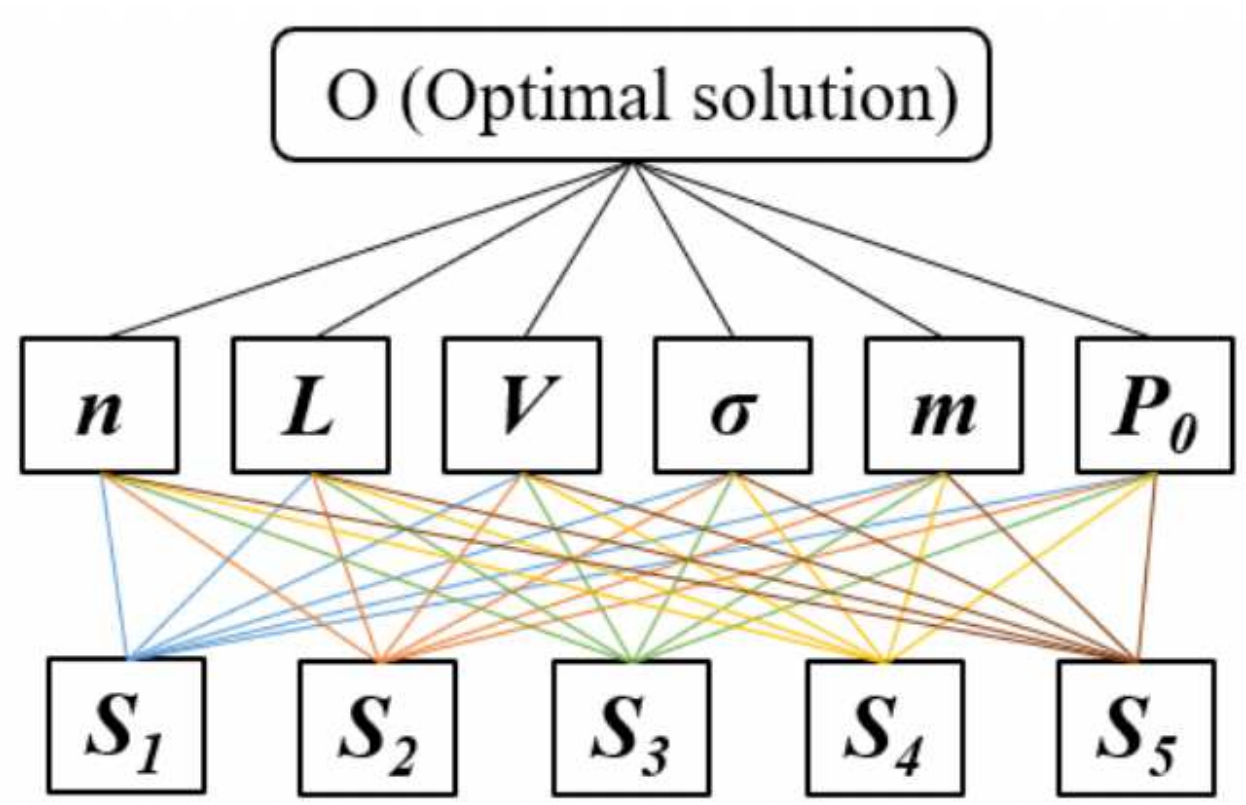

Figure 8

Evaluation hierarchy diagram of the evaluation of the ICS 


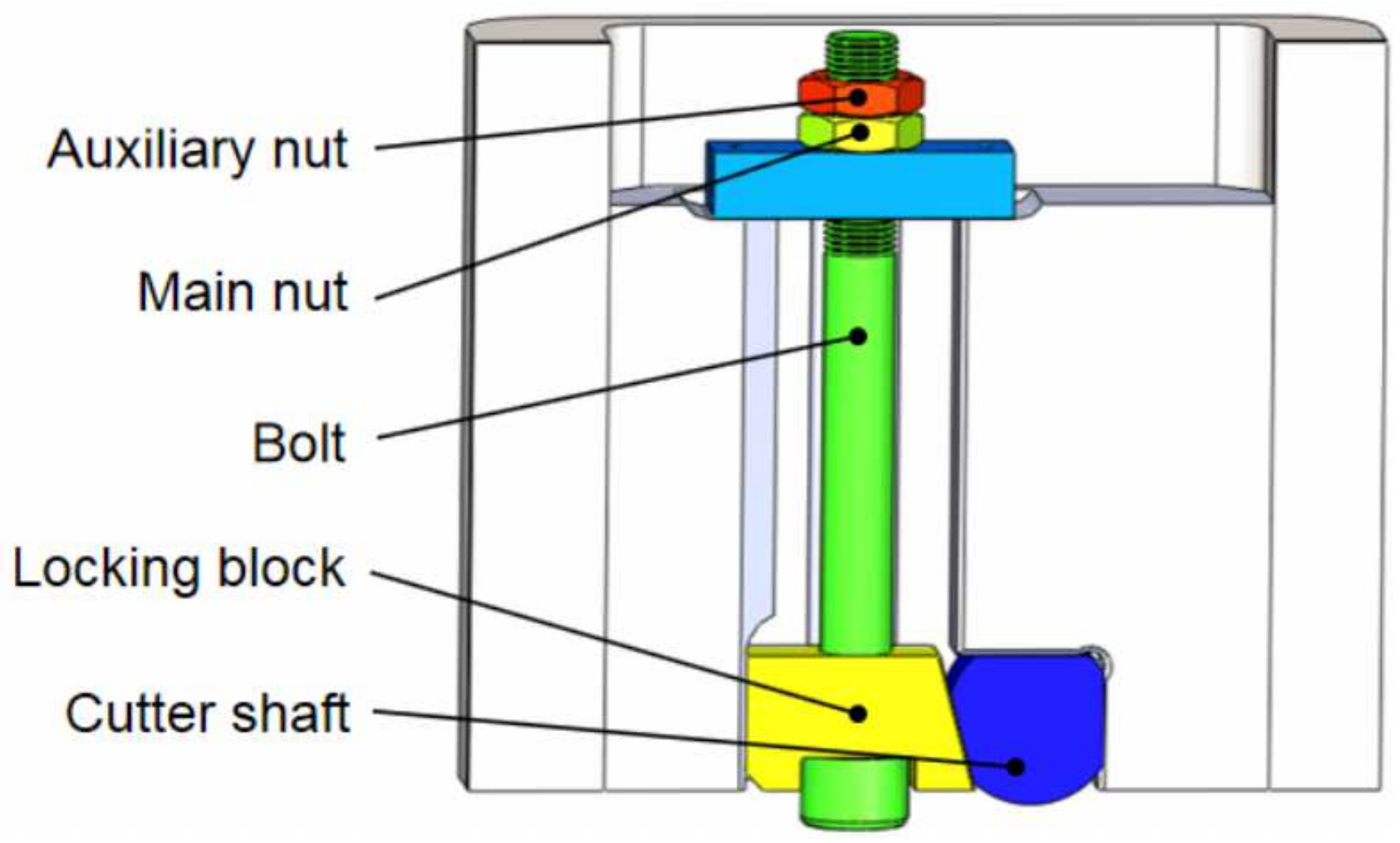

Figure 9

Schematic diagram of anti-loosening structure of the TCS

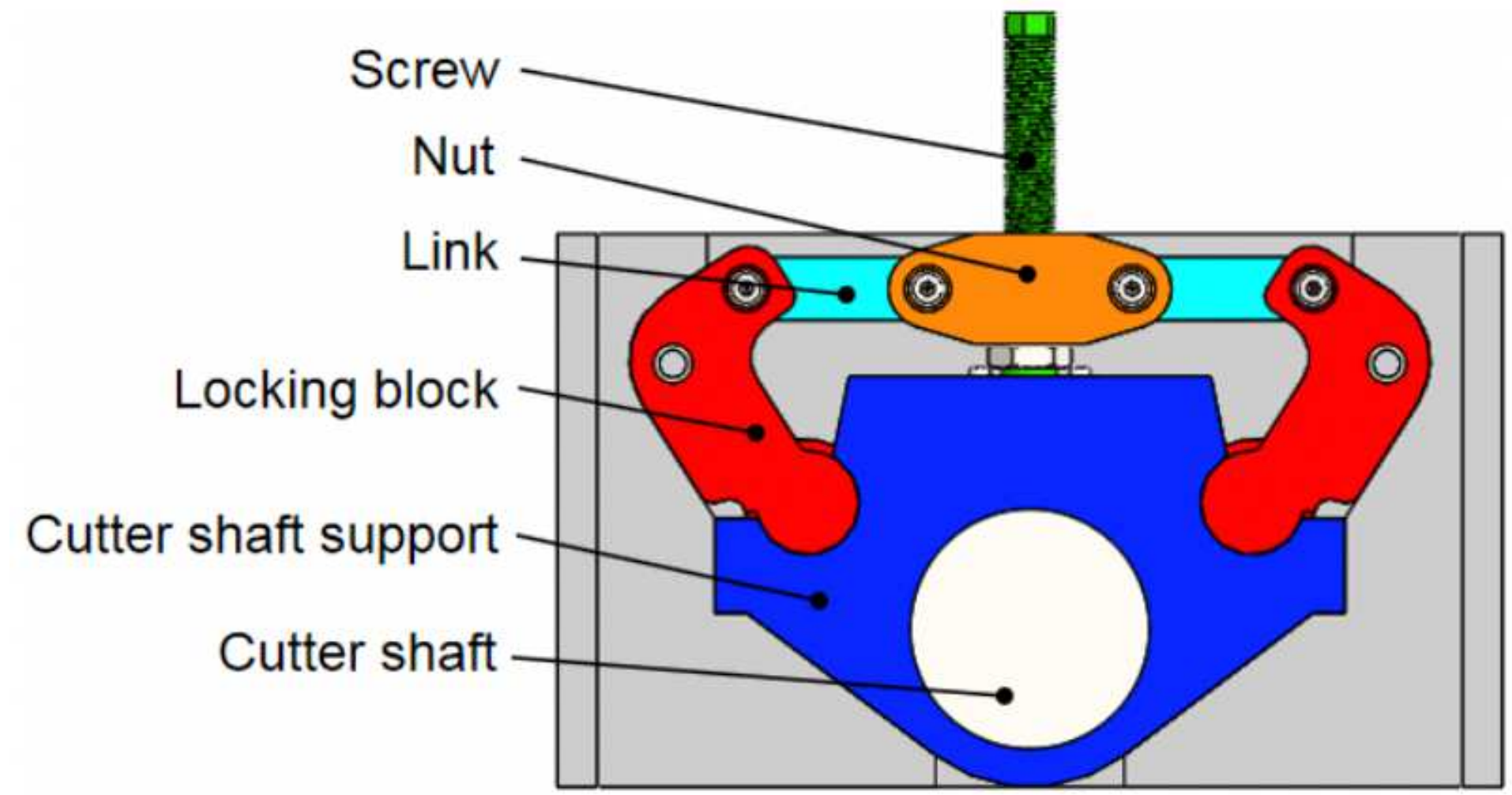


Figure 10

Schematic diagram of anti-looseness structure of novel the TBM ICS

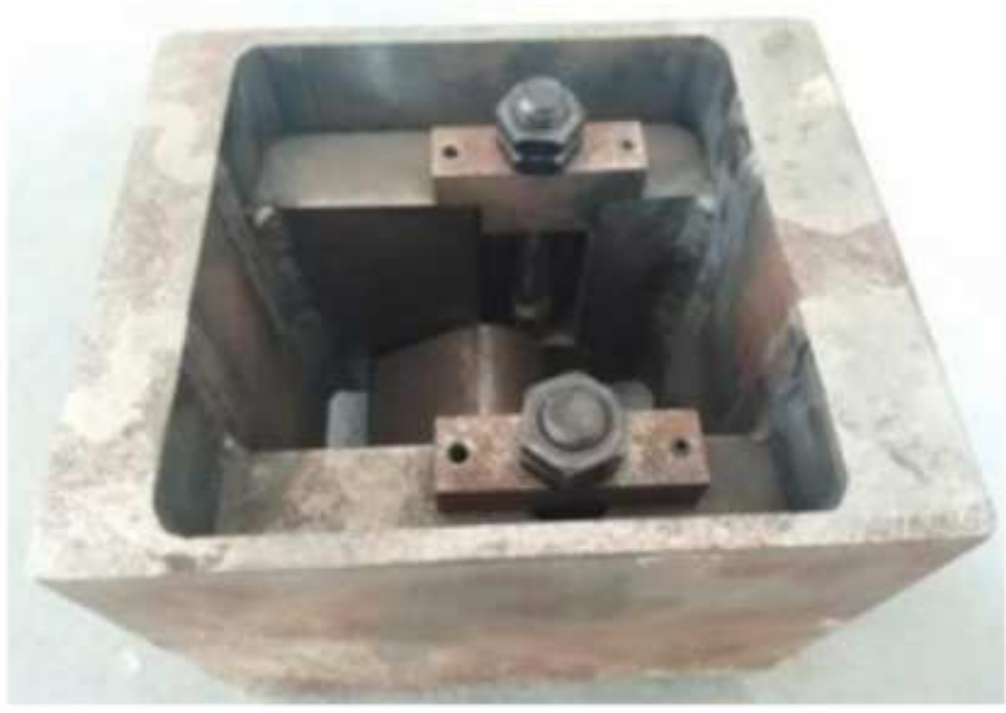

(a)

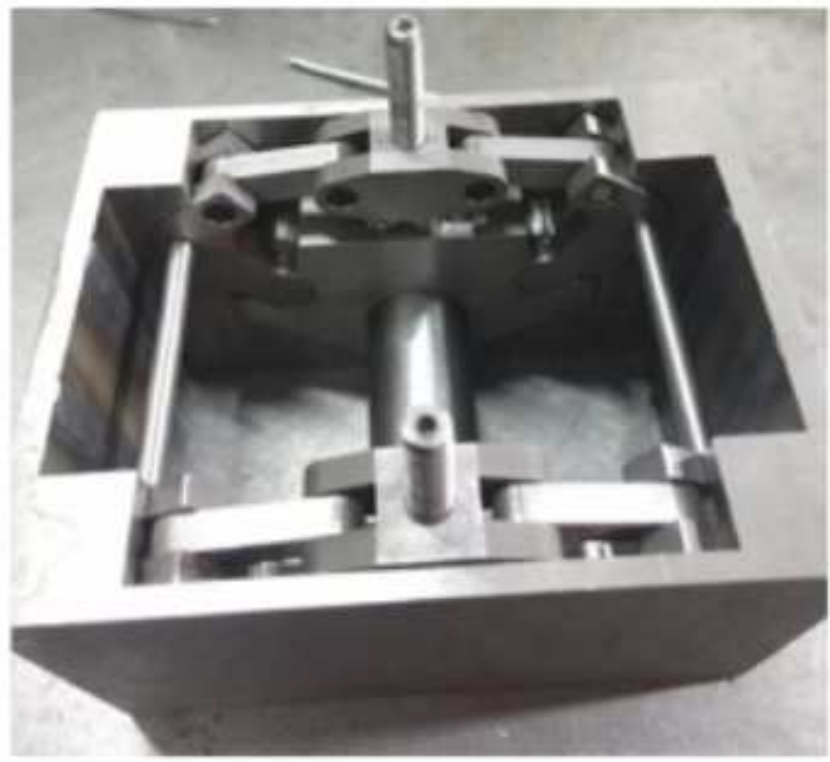

(b)

\section{Figure 11}

Scale sample of the TCS and the novel TBM ICS

\section{Measuring location}

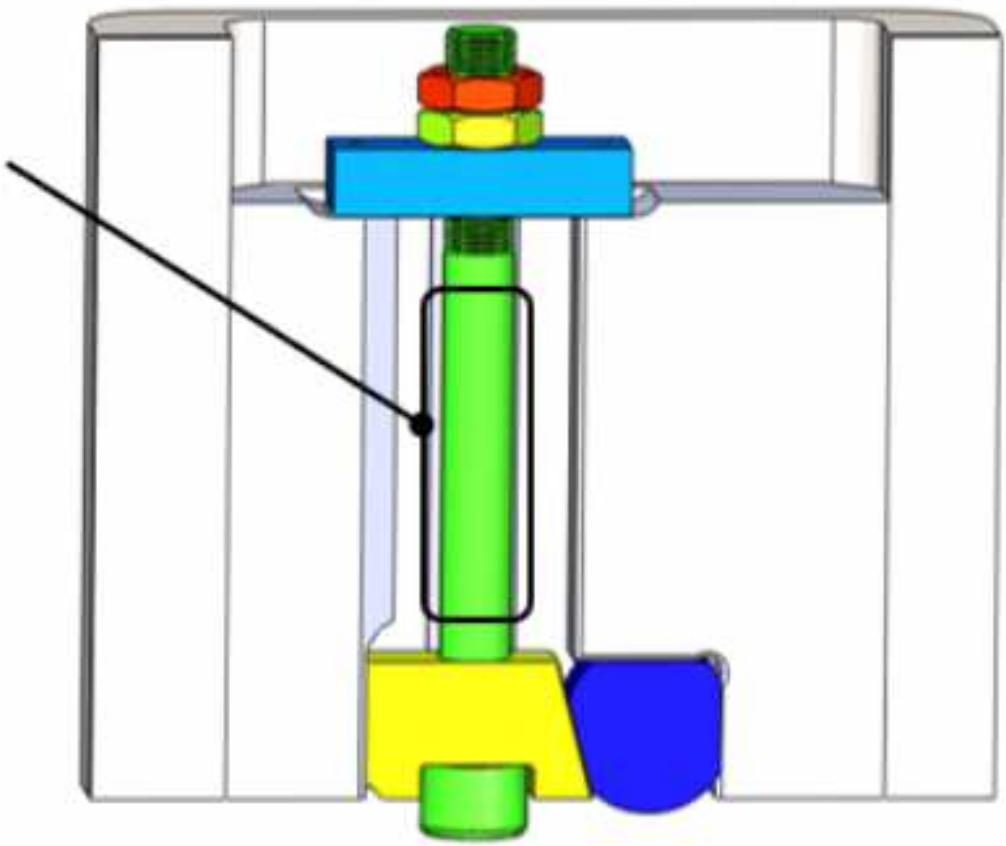

Figure 12

Measuring location of the TCS 


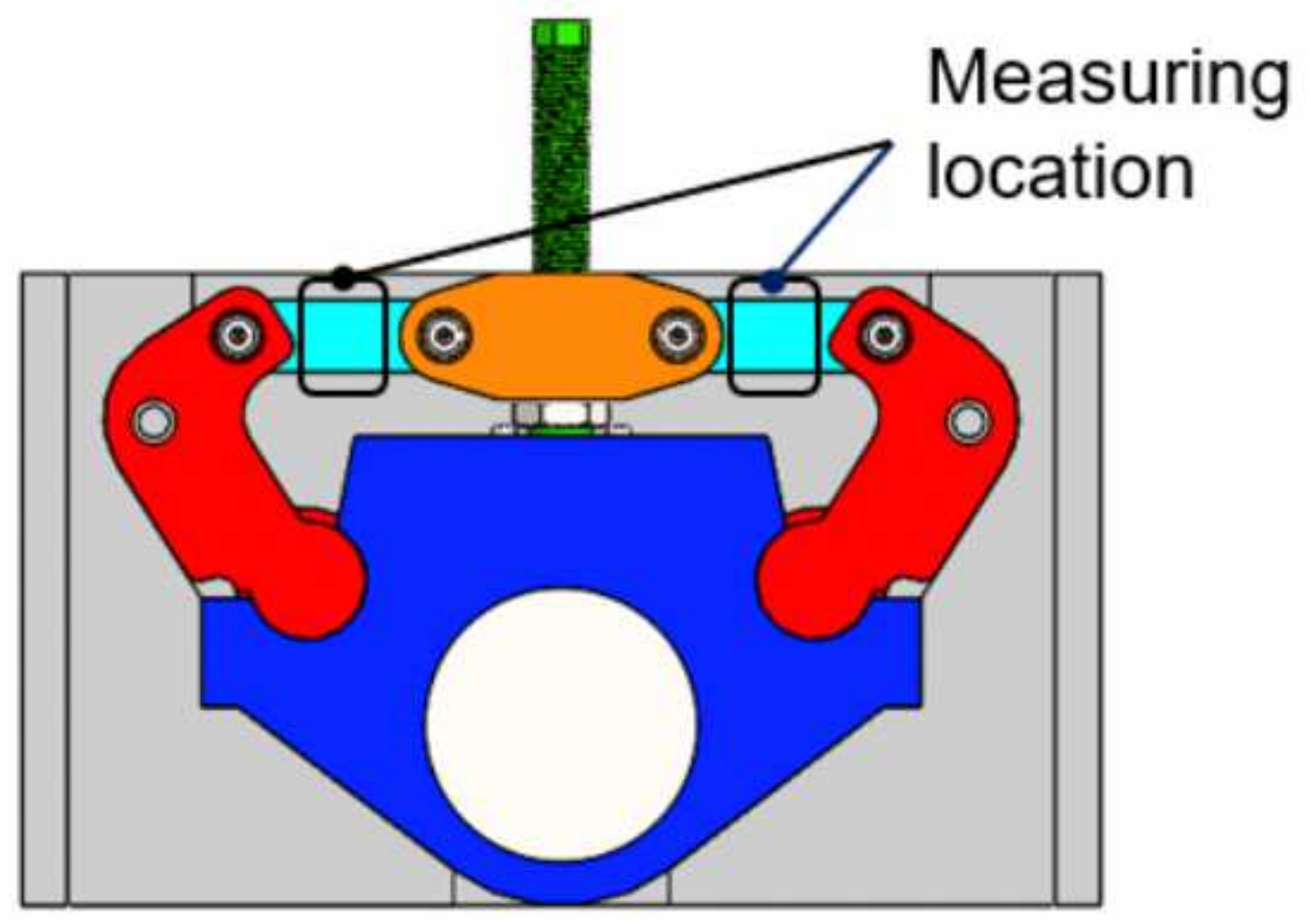

Figure 13

Measuring location of the ICS

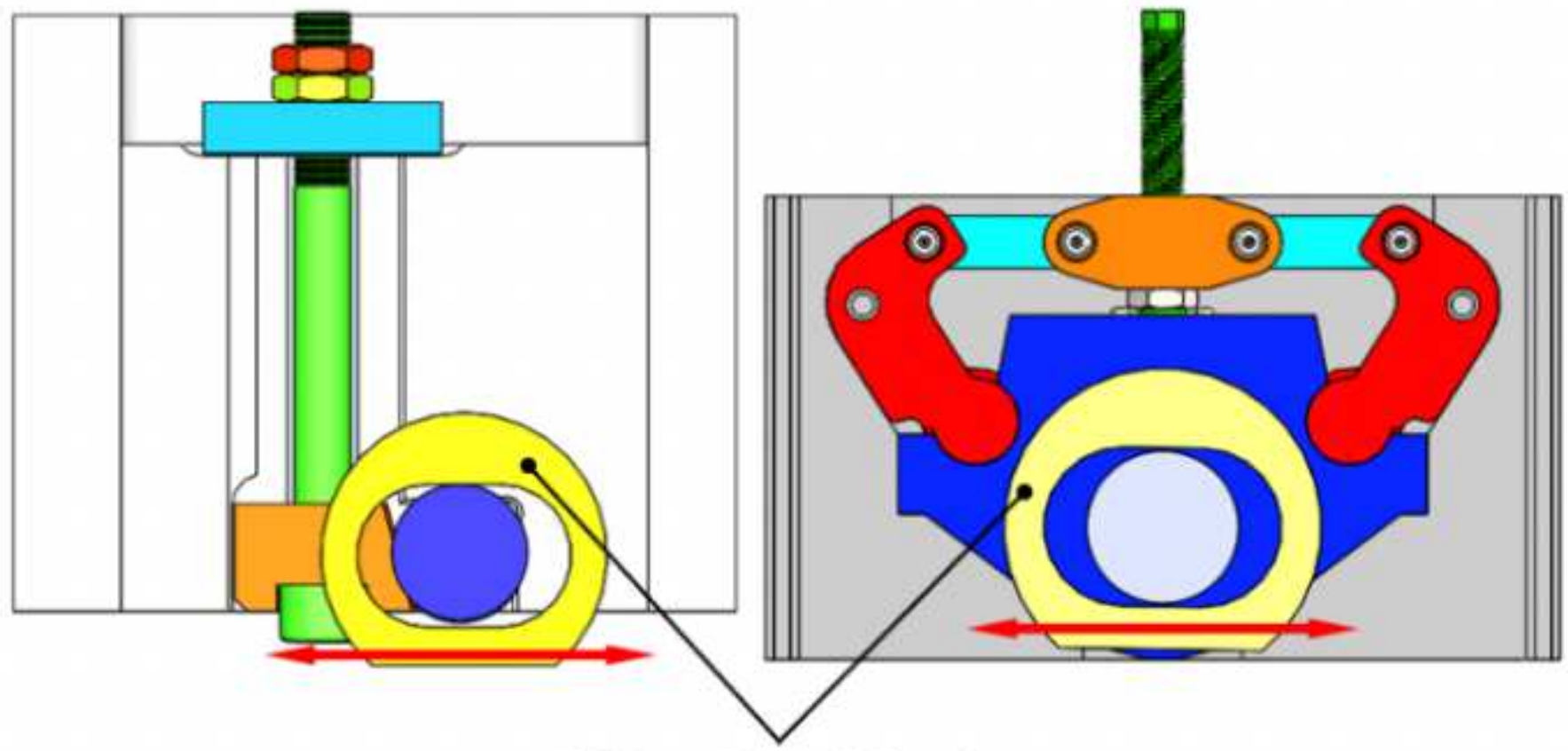

Vibrating block

Figure 14

Schematic diagram of the vibration block position 


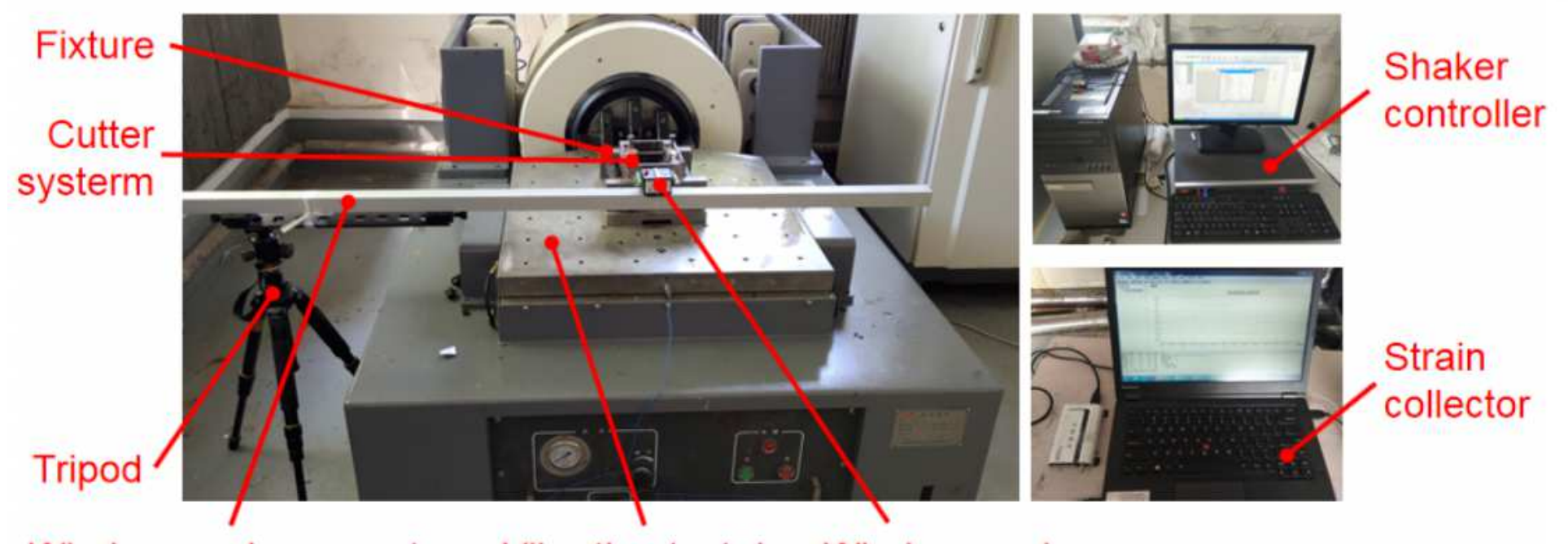

Wireless node support Vibration test rig Wireless node

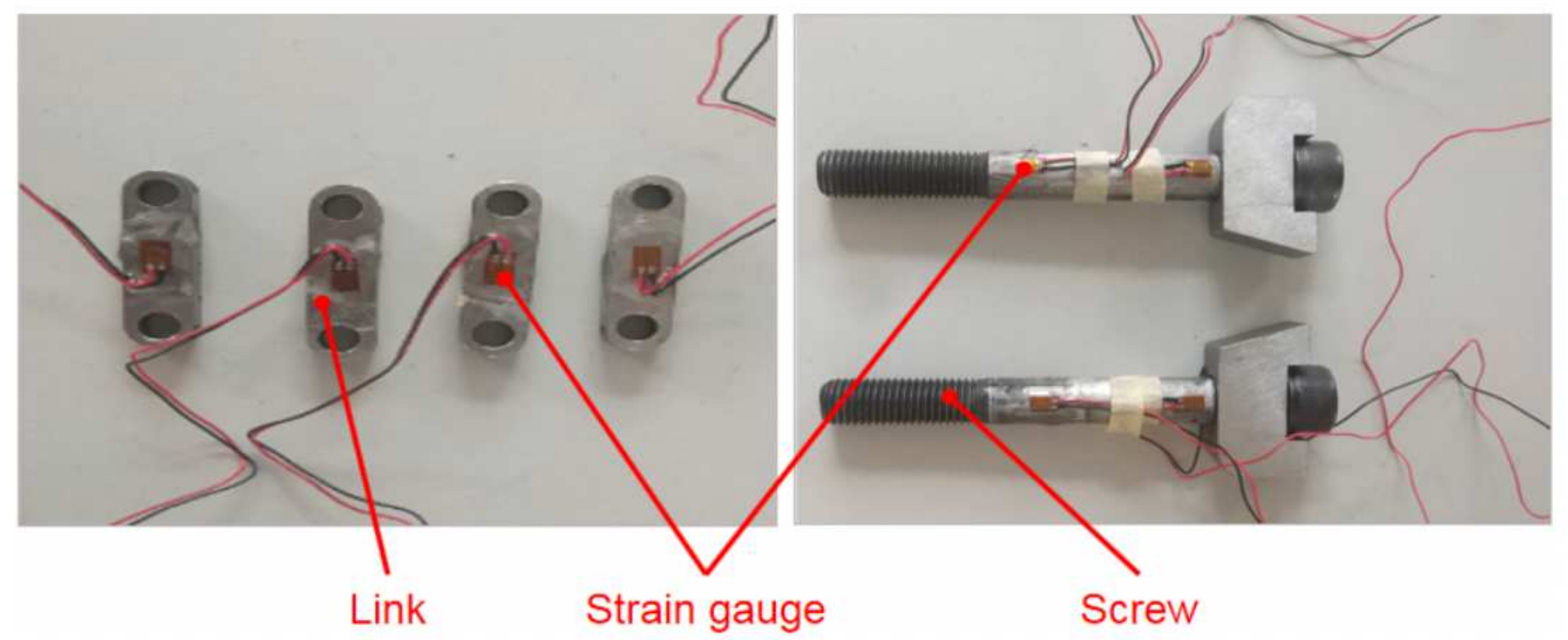

Figure 15

Pictures of anti-loosening performance test system of the cutter system 


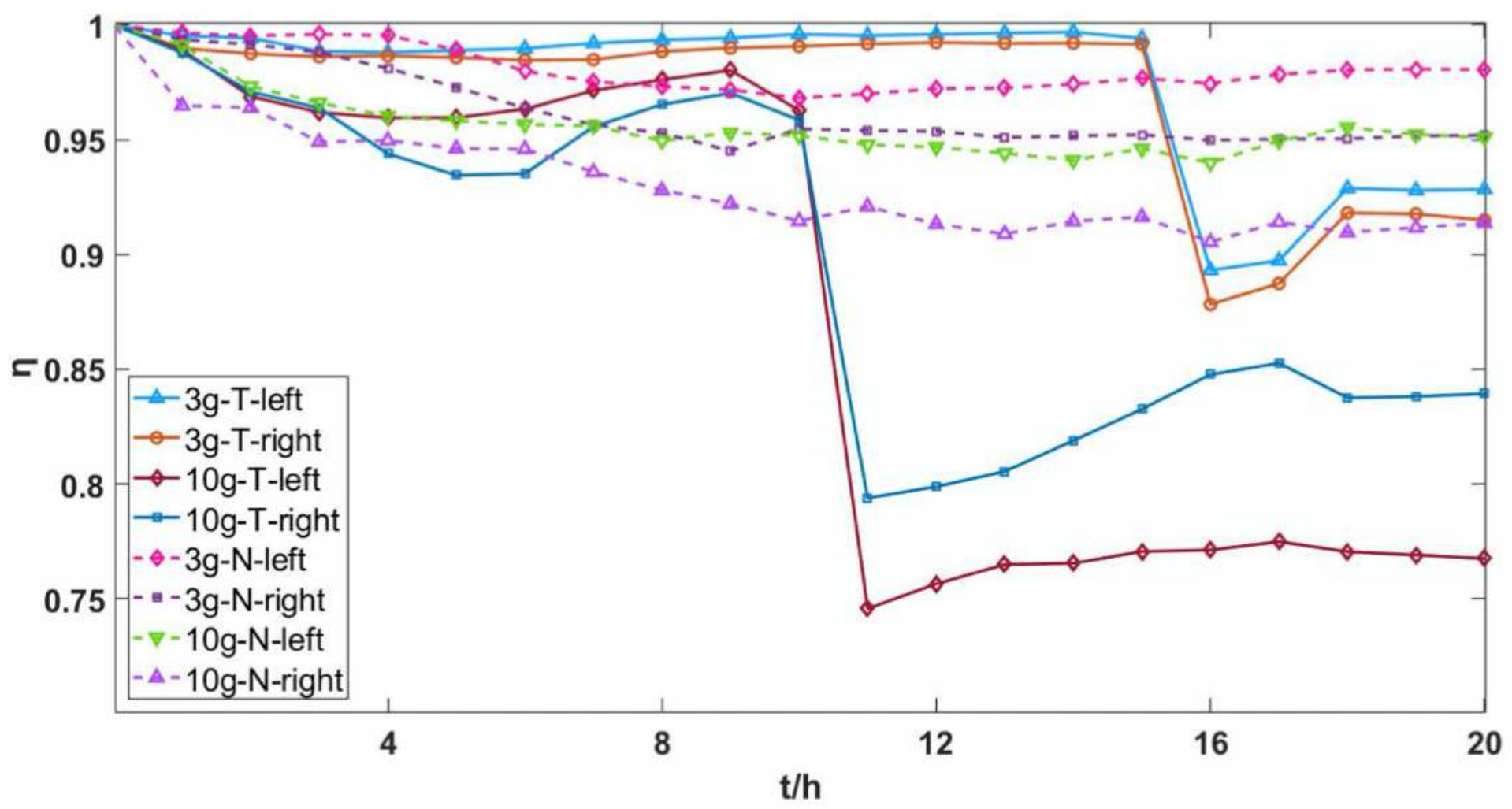

Figure 16

The values change of $\mathbb{\nabla}$ of two types of cutter systems under two kinds of working conditions 